\title{
MUJERES Y SUS REPRESENTACIONES SOCIALES DE GÉNERO EN EL CIP BAHÍAS DE HUATULCO, MÉXICO
}

\author{
Martha Marivel MENDOZA ONTIVEROS*; Marcelino ALEJO PACHECO*: \\ Gregoria RODRÍGUEZ MUÑOZ*; María José FERNÁNDEZ ALDECUA** \\ *Universidad Autónoma del Estado de México; **Universidad del Mar (México) \\ marivelmo@hotmail.com,marsalejo@yahoo.com,gregoria11@yahoo.com.mx, marita. \\ fernandez.aldecua@gmail.com
}

\section{WOMEN AND SOCIAL REPRESENTATIONS OF GENDER CIP HUATULCO BAYS, MEXICO}

Resumen: En este trabajo se exponen los resultados de un estudio que buscó conocer si la representación social de la mujer se ve modificada por el hecho de vivir o trabajar en un contexto turístico. Gracias al uso de entrevistas a profundidad, se obtuvo que el turismo proporciona a las mujeres la posibilidad de integrarse a la vida laboral remunerada y permite el contacto con hombres y mujeres cuyas conductas no se asemejan a las conductas de los habitantes de las zonas turísticas. Los roles modificados o nuevos pueden dar origen a una percepción del yo individual, que se transmite al yo colectivo y, por tanto, incide en la modificación de la memoria colectiva. Dicha resignificación de la representación social de la identidad de género implica el proceso por el cual las mujeres buscan dejar de ser cosas o seres-en-sí, para caminar hacia la posibilidad de ser sujetos.

Abstract: This paper presents the results of a study whose pursue was to know if the woman social representation is modified by the fact of living or working in a tourism context. Thus, by using in-depth interviews, it was found meant that there is a change in the roles that individuals have played traditionally, economically provides women the opportunity to be integrated to paid work life and socially allows contact with men and women whose behaviors do not resemble the behavior of people in the tourist areas. New or modified roles can lead to a perception of the self, which is transmitted to the collective self and, therefore, affects the collective memory modification. It is worth noting that the redefinition of the social representation of gender identity involves the process by which women seek to stop being things or beings-inthemselves, to pursue the possibility of being a subject, having the ability to name and signify in the world, by starting a process of deconstruction of their representation.

Palabras clave: Representaciones Sociales; Turismo; Mujer; Efectos Culturales; Trabajo Remunerado Social Representations; Tourism. Women; Cultural Effects; Work Paiden 


\section{Introducción}

La importancia económica y sociocultural del turismo es un hecho que no puede negarse hoy en día a escala global, esta relevancia se ve acompañada por una densa y compleja trama de influencias, cambios e impactos, inducidos por sus actividades e infraestructura sobre las culturas y los entornos receptores de turistas, pues si cambian los espacios, cambian las culturas (Nogués, 1995). Luego de cinco décadas en las que este fenómeno se ha extendido por todas las regiones del planeta, hoy puede verse que el turismo -y los espacios que genera- alteran, modifican y recrean en esos lugares, bienes y actividades que constituyen formas relevantes de expresión de la cultura y modos de vida propios de cada pueblo. Discernir si el turismo es benéfico o pernicioso, al analizar sus influencias para llevar a cabo una planificación coherente del desarrollo sostenible en las zonas económicamente periféricas y abocadas a recurrir al turismo como actividad estructural (Nogués, 1995), es una tarea de suma importancia.

La antropología en el estudio de los procesos de cambio cultural generados por el turismo ha mostrado, por ejemplo, que la presencia del "otro" genera símbolos de estatus que modifican el universo simbólico de las comunidades receptoras. En otras palabras, comienza un proceso de inversión simbólica que influye en la manera de autopercepción. Según este patrón, las comunidades receptoras se verán a través de los ojos de los turistas, el principio de emulación provoca cambios estructurales y de comportamiento en dichas comunidades (Nogués, 1995).

Por lo anterior, no es de extrañar que los estudios de género pronto pusiera los ojos en contextos turísticos debido a que pudo detectarse que uno de los efectos o cambios culturales ocasionados por el turismo se encuentra en las relaciones de género. Esta última aproximación, es decir, la perspectiva de género, se incorporó en los estudios turísticos a partir de la década de los setenta para concebir al turismo como relaciones de género entre individuos, grupos, categorías sociales, tipos de turismo y naciones. Bajo esta perspectiva hombres y mujeres están involucrados de diferente manera en la oferta y el consumo del turismo. Es decir, las realidades formadas por el género dan forma a la comercialización del turismo, a las motivaciones de los huéspedes, así como a las acciones de los anfitriones (Swain, 1995).

Esta serie de trabajos que han abordado al turismo con perspectiva de género lograron visibilizar la realidad turística a partir de las variables sexo y género, así como sus manifestaciones en lo cultural, lo étnico y lo histórico. La mayoría de estas investigaciones lograron entrever a las mujeres que hasta ese momento había permanecido ocultas en los estudios del turismo, igual que en otros sectores de la economía, ejemplos de tales investigaciones las representan los trabajos de Swain (1989) y Wilson (1979). Más adelante, en la década de los noventa, se realizan trabajos que hacen análisis de género y desarrollo debido a que se asumió que por la asignación de roles socialmente distintos y con desigual valoración, los hombres y las mujeres tienen problemas y necesidades diferentes que no deben perderse de vista en el momento de plantearse programas de desarrollo. En este sentido hubo una insistencia en que los efectos e impactos del turismo se presentan de forma diferenciada y desigual por género y, por lo tanto, las políticas y estrategias de desarrollo debían ser también diferentes (Swain, 1993 y 1995, García Ramón, 1995, Renzi, 2009). De manera particular, la investigación turística sobre el desarrollo económico con perspectiva de género ha mostrado los tipos y los efectos del trabajo generado para hombres y mujeres debido a las nuevas oportunidades de empleo e ingreso.

En otro grupo de trabajos se incorpora el legado de Foucault en cuestiones de dominación, subyugación y normalización, así se concibe al turismo como un elemento que se inserta en una estructura de poder y, por tanto, presta mayor atención a la desigualdad de 
género (Wilkinson y Pratiwi, 1995, Diéguez Castillón, et.al. 2010, Tucker, 2007, McKenzie Gentry, 2007). De esta forma, se denuncia que en un entorno turístico también se encuentra una situación de desventaja para las mujeres con relación a los hombres que se materializa en su marginación, falta de acceso a los recursos, a la educación, así como su vulnerabilidad ante la pobreza y la violencia. De esta forma, la mayoría de investigaciones, así como la evidencia empírica han revelado que los empleos que las mujeres encuentran en el sector turístico constituyen una extensión de las labores domésticas (lavar, limpiar, cocinar, servir), sólo que ahora obtienen un salario por ello. Asimismo, se ha evidenciado que existe desigualdad en materia de salarios, falta de acceso a capital y tecnología, discriminación ocupacional debido a la maternidad y lactancia (Sigüenza 2011).

De igual forma, el dato empírico permite constatar lo planteado por Bourdieu (2003) en el sentido de que así como el trabajo doméstico de las mujeres se considera el medio para mantener la solidaridad y la integridad de la familia, por lo que son las encargadas de la gestión del capital simbólico de las familias, esa función se traslada al seno de la empresa turística, que les pide que desempeñen las actividades de presentación y de representación, de recepción y acogida (azafata de vuelos, azafata de autobús, azafata de congresos, acompañante, etc.), igual que la gestión de grandes rituales burocráticos (publirrelacionista, organizadora de eventos) que, como los rituales domésticos, contribuyen al mantenimiento y al incremento del capital social de las relaciones y del capital simbólico de las empresas.

Por otra parte, algunos estudios más optimistas han postulado que el trabajo en el sector turístico puede conducir a cambiar la situación y la condición de la mujer, a ganar independencia e incluso a habilitarla para el poder o empoderarla, entendido esto como la capacidad de decidir sobre su propia vida, a la afirmación y satisfacción de sus necesidades y a la consecución de sus objetivos (Lakovidou, 2002, Sparrer, 2003, Treminio Sánchez, 2005, Vandegrift, 2008). Cones (1995) sostiene por ejemplo que las oportunidades de trabajo femenino en el ámbito turístico han permitido a las mujeres adoptar formas de pensamiento similares a las de las turistas y con ello rechazar normas tradicionales de su comunidad que las pone en desventaja social y económica respecto a los hombres de su comunidad.

Ante este panorama cabe preguntarse si el contacto cultural ocurrido con ocasión del turismo, así como las oportunidades de empleo que éste proporciona a las mujeres, ha modificación su autopercepción, es decir, la manera en cómo se piensan y se definen a sí mismas. Para abordar dicha temática consideramos que la clave explicativa la puede proporcionar la teoría de las representaciones sociales, pues por el hecho de que las mujeres trabajen y puedan tomar algunas decisiones económicas no puede inferirse que se haya empoderado (Wilkinson, 1995; Caballé, 2000, Díaz Carrión, 2010) o que se haya constituido en agente -según la teoría de la estructuración de Giddens (1995)-, mucho menos aún que se hable de mujeres como sujeto (Touraine 1997), lo anterior como efecto de vivir o trabajar en un destino turístico.

Si el turismo posibilita que las mujeres salgan de la esfera doméstica para ingresar al ámbito público gracias al trabajo remunerado, así como también las expone al contacto con nuevas fuentes de información por el contacto con los turistas, con sus estilos de vida, sus cosmovisiones, su discurso, y a las representaciones sociales de los migrantes que llegan atraídos por la oferta de trabajo, pudiera estar permitiendo que la representación social de las mujeres pueda haberse modificado ya que una representación social se transforma a partir de la integración de nuevos elementos cognitivos a la representación preexistente por medio de la objetivación y el anclaje (Tranakjit y Scott, 2009).

En la actualidad, cuando las actividades turísticas se han consolidado en muchos territorios y la llegada de turistas y su afluencia estacional es parte constitutiva de ellos, no es posible ignorar la capacidad estructurante del hecho turístico en las sociedades receptoras. Lo anterior remite a estudiar las dinámicas sociales y culturales promovidas por la llegada de turistas en el conjunto de prácticas que surgen a partir de la relación mercantil 
que se establece entre la población local y la visitante. Si se entiende a la cultura como la organización social de significados interiorizados de modo relativamente estables por los sujetos en forma de representaciones compartidas (Giménez, 2005), entonces la teoría y la metodología de las representaciones sociales son una vía fructífera para el análisis de las formas de cultura interiorizada desde un punto de vista diacrónico y sincrónico.

Con base en lo anterior, desde una perspectiva de género, en este artículo se presentan los resultados de un trabajo de investigación en donde se buscó conocer las representaciones sociales de género de mujeres que viven o trabajan en el CIP Bahías de Huatulco, México y escudriñar su relación con el turismo.

El trabajo se desarrolla a partir de la perspectiva teórica: turismo, género y representaciones sociales, luego se describe el entorno del estudio, enseguida se narra la metodología empleada para la generación de datos, posteriormente se presentan los resultados alcanzados y se finaliza con las conclusiones.

\section{Perspectiva teórica}

\section{La Identidad de Género}

La construcción de la identidad de género es un fenómeno en el que intervienen los procesos de socialización primaria y secundaria. De esta forma, la subjetividad o el advenimiento en sujeto inicia con la determinación social de género a partir del cuerpo; en cambio, la identidad masculina o femenina es producto de una construcción simbólica desde lo sociológico, lo cultural, desde la vida cotidiana, es producto de un proceso largo que va tejiendo una urdimbre a partir de la interacción con el medio familiar y social.

Así la identidad de género no es una manifestación natural y espontánea del sexo o la expresión de características intrínsecas y específicas de los cuerpos sexuados en masculino y femenino, sino que los cuerpos son como una mole de piedra sobre la cual se esculpen los modelos y representaciones de la masculinidad y la feminidad difundidos por las formas culturales hegemónicas de cada sociedad. La vida cotidiana, los discursos, el cine, los medios de comunicación actúan sobre dichas representaciones. De este modo, el género implica valores, normas, prescripciones, representaciones, comportamientos que definen la identidad masculina y la femenina a nivel social; el género ordena el proceso social de la vida cotidiana y se construye al interior de las instituciones sociales más importantes.

Puede decirse, por tanto, que la identidad de género es producto, pero también es proceso porque está siempre haciéndose, de ahí que Lorber (1994 citado en Banchs Rodríguez, 2000) proponga usar el término gendering que alude al permanente proceso de hacer género, en lugar de sólo reproducir género. Así cuando un hombre sube al transporte público con su bebé y le lleva a la guardería, está produciendo género.

$\mathrm{Si}$ aceptamos que la identidad de género es un proceso, entonces es posible aceptar también que tales identidades pueden re-definirse, re-significarse, lo cual desemboca en su cuestionamiento. La posibilidad de este cuestionamiento no puede ponerse en duda, pues hacerlo indicaría que se niega la posibilidad de modificación de los patrones de conducta, de la modificación de los comportamientos, de la alteración del orden social y de las relaciones entre los individuos, de modo que viviríamos en sociedades inmutables; sin embargo, cabe preguntarse qué origina el cuestionamiento de la identidad de género.

La teoría de las representaciones sociales, teoría dialéctica que vincula pensamiento y acción, es el instrumento mediante el cual el científico social puede definir y articular las re-significaciones de las identidades de género vinculadas a la cultura, raza, edad y clase social. Sin bien Banchs Rodríguez (2000) alude a la poca flexibilidad y a la calidad de arquetipos trans-generacionales de las representaciones de género, éstas cambian aunque sea de manera lenta. 


\section{Representaciones Sociales: Nociones Preliminares}

La noción de representación social encuentra parte de su pertinencia en la exigencia de profundizar en los vínculos existentes entre un sistema de conocimiento práctico (opiniones, imágenes, actitudes, estereotipos, creencias, valores) y los contextos de actuación interindividuales o intergrupales (Moscovici, 1989). Moscovici en cada uno de sus escritos, fue renovando y estimulando la fecundidad semántica del término, razón por la cual años más tarde Denise Jodelet (1984) planteara que la noción de representación social concierne a:

- La manera en que nosotros, sujetos sociales, aprendemos los acontecimientos de la vida diaria, las características de nuestro medio ambiente, las informaciones que en él circulan, a las personas de nuestro entorno próximo o lejano.

- El conocimiento espontáneo, ingenuo o de sentido común por oposición al pensamiento científico.

- El conocimiento socialmente elaborado y compartido, constituido a partir de nuestras experiencias y de las informaciones y modelos de pensamiento que recibimos y transmitimos a través de la tradición, la educación y la comunicación social.

- Conocimiento práctico que participa en la construcción social de una realidad común a un conjunto social e intenta dominar esencialmente ese entorno, comprender y explicar los hechos e ideas de nuestro universo de vida.

- Son al mismo tiempo producto y proceso de una actividad de apropiación de una realidad externa y de elaboración psicológica y social de esa realidad. Son pensamiento constituido (productos o contenidos), en la medida en que los sujetos le asignan un contenido y la organizan en discurso sobre la realidad, y constituyente (proceso o acción), esto es un movimiento de apropiación de la realidad a través de un proceso mental, pero en un contexto de producción colectiva.

Una de las principales fuentes de una representación social es la experiencia acumulada de la humanidad a lo largo de la historia, proceso que da como resultado la cultura, que asume características concretas de acuerdo con factores socioeconómicos particulares. Esta experiencia llega a través del lenguaje en forma de memoria colectiva plasmada en tradiciones, creencias, normas y valores.

Otras fuentes de una representación es la comunicación social en sus diferentes formas, dentro de la que puede ubicarse a los medios de comunicación como transmisores de conocimientos, valores, modelos, informaciones y la comunicación interpersonal. En esta última destacan las conversaciones cotidianas en las cuales recibimos y ofrecemos todo un cúmulo de información.

\section{Teoría del Núcleo Central: Una Aproximación Estructural}

La teoría del núcleo central plantea que la estructura de una representación social está formada por un código central o núcleo y un entramado de elementos periféricos. La hipótesis de Abric (2001) es que el núcleo constituye la representación estable, coherente, consensual y está influido por la memoria colectiva y del sistema de valores del grupo, mientras que el sistema periférico pragmatiza o contextualiza permanentemente las determinaciones normativas, lo que genera que tales representaciones sociales sean estables y a la vez dinámicas y plurales. En este planteamiento inicial, el núcleo es generador de sentido $\mathrm{y}$, en consecuencia, es indispensable para el funcionamiento y la conservación de la representación, en cambio los elementos periféricos serían más individualizados y fluctuantes, es decir, dependen más del contexto inmediato (Rodríguez Salazar, 2011). 
Moscovici planteó (citado en Banchs Rodríguez, 2000) que las representaciones sociales son al mismo tiempo una teoría general y una teoría particular. General porque constituyen una visión general de la sociedad en su conjunto y particular porque son formas colectivas de pensamientos y creencias producidas bajo las presiones o crisis de la sociedad.

Abric (1993) incorpora el concepto de Moscovici de los thematas al enfoque estructural de las representaciones sociales, los cuales son parte del núcleo central y constituyen temas que persisten, que tienen un poder generador debido a que constituyen una diversidad de contenidos concretos que pueden penetrar en función del contexto, significados y reglas no negociables. Estos temas no se apoyan en hechos, sino en reglas de vida, y representan, de esta forma, una realidad supra-individual o hard core (Banchs Rodríguez, 2000). Constituyen una parte no cognitiva, conocimiento irreflexivo, inconsciente, escasamente cuestionado (Rodriguez Salazar, 2005), prejuicios asumidos como verdaderos en la cultura de un grupo que pueden asumir distintas formas cognitivas. Ejemplos de estos thematas serían las creencias como la de "la mujer por naturaleza posee un instinto maternal" o "somos lo que comemos".

La teoría del núcleo central y los themata dan pauta a entender los procesos de transformación de las representaciones sociales. Abric (1993) habla de tres procesos: a) la transformación de resistencia donde los elementos que cambian son sólo periféricos; b) transformación progresiva que ocurre cuando el núcleo central es modificado por la integración de nuevos elementos sin fracturar los elementos del sistema central; y c) la transformación total, directa y completa del núcleo central que sucede cuando los mecanismos de defensa son incapaces de cumplir su rol.

Del mismo modo, dicha teoría evita que se asuma que las representaciones sociales implican consenso, ya que admite la posibilidad de variaciones individuales. Con antelación Moscovici, (1988 citado en Rodríguez Salazar, 2003 y 2005; Banchs Rodríguez, 2000) aclaró que el consenso que caracteriza a las representaciones sociales es dinámico, no significa uniformidad ni excluye la diversidad. De ahí que proponga tres tipos de representaciones:

- Representaciones sociales hegemónicas, cuando éstas son compartidas por todos los miembros de un grupo altamente estructurado, sin que hayan sido producidas por el grupo. Tales representaciones parecen ser uniformes y coercitivas y prevalecen implícitamente en toda práctica simbólica o afectiva. - Representaciones sociales emancipadas, cuando son producto de la circulación de conocimientos e ideas que esbozan subgrupos que están más o menos en contacto. Estas representaciones tienen cierta autonomía y resultan de compartir interpretaciones y símbolos.

- Representaciones sociales controversiales mismas que son generadas en situaciones de conflicto o controversia social, y que la sociedad como un todo no comparte. Éstas surgen de relaciones antagónicas entre los miembros de una sociedad determinada. Estas representaciones surgen debido a un cambio en el contexto, el cual suscita un conflicto cognitivo que obliga a la resignificación.

No obstante, Rodríguez Salazar (2005) propone que los tres tipos de representación son más bien estados que coexisten en grados diversos al interior de una misma representación, en el entendido que constituye un sistema holístico. La presencia de mayor contenido hegemónico, de contenidos emancipados o de contenidos polémicos haría posible identificar la representación social de un grupo social dado:

- Contenidos hegemónicos: son colectivamente compartidos (probablemente a nivel macro social) legítimos y menos susceptibles de cuestionamiento. Estos contenidos se hacen visibles en el discurso a través de enunciados afirmativos o 
descriptivos que constatan, que explican significados sin dudar de su existencia y su conveniencia universal. Son creencias (thematas) simbólicamente poderosas que se asumen como "naturales" o "evidentes".

- Contenidos emancipados: se refiere a creencias y valores que sostienen grupos sociales específicos, compartidos en un momento dado. Estos significados parten de la fuente de autoridad de la sociedad o el grupo social (a diferencia de los hegemónicos cuya fuente de autoridad es la naturaleza). En este caso, la aceptación de un contenido cultural estaría en función de la pertenencia a dicho grupo.

- Contenidos polémicos: son aquellos que son discutidos abiertamente dentro de un grupo social; son contenidos que se asumen con cargas de relativismo, los cuales generan dudas, críticas o particularización de significados. Son contenidos que amenazan el themata de la representación social en términos de fuerza simbólica, aceptación y legitimidad social. Esta clase de contenido socava la validez universal construida por los contenidos hegemónicos, para hacer valer excepciones de significación y práctica.

Los contenidos hegemónicos, emancipados y polémicos indicarían, según Rodríguez Salazar (2005), grados decrecientes de divergencia grupal o individual, así como grados de decremento de fuerza simbólica, aceptación y legitimidad social, así como sus tendencias de transformación (Rodríguez Salazar, 2003).

\section{El CIP Bahías de Huatulco}

Al igual que otros CIP emprendidos por el FONATUR, Bahías de Huatulco supuso la creación de una ciudad turística a partir de cero, realizada con la convicción de establecer polos de desarrollo en zonas marginadas, diversificar la oferta turística y buscar nuevas formas para captar divisas. De esta forma, el estado de Oaxaca tenía la oportunidad de crear un polo de desarrollo regional que evitara su rezago frente al crecimiento del resto del país y al mismo tiempo propiciara el arraigo y mejoramiento de los niveles de vida de sus habitantes (De la Madrid, 2011). En el caso de Huatulco, las autoridades intentaron un aprovechamiento diferente a través de la planeación así como de las herramientas para un desarrollo eficiente y sustentable para anticiparse a los conflictos que pudieran surgir entre la comunidad local y los gestores turísticos.

En respuesta al escenario que se pronosticaba, el FONATUR conformó un equipo de profesionales, denominado Desarrollo de la Comunidad, encargado de gestionar la problemática social derivada de la expropiación a través de una serie de actuaciones, entre ellas: la gestión de indemnizaciones a comuneros y la capacitación de la población (López Guevara, 2010). No obstante, los cursos de capacitación fueron suspendidos por los recortes presupuestales del sexenio siguiente y porque la población local fracasó en sus negocios debido a que no supieron o no pudieron competir con los negocios de la gente recién llegada. Asimismo, los pagos de la expropiación fueron rápidamente gastados en bienes que antes era imposible adquirir: automóviles, televisores, televisión de paga, equipos de audio y video (Morales Gómez, 2009). De esta forma las transformaciones sociales y económicas no beneficiaron a los locales, antes bien, para el 2000 el número de inmigrantes había superado al de los locales.

La construcción de Huatulco dio inicio en 1984 con la expropiación de alrededor de 21.000 hectáreas. Con el propósito de destinarlas al CIP y siguiendo un Plan Maestro determinado. Al momento de la expropiación, el municipio contaba con 2.500 habitantes distribuidos en rancherías y caseríos a lo largo de la carretera Salina Cruz- Pochutla, entre los ríos 
Copalita, Coyula y la franja costera, cuyas actividades económicas eran de autoconsumo y la pesca a pequeña escala, principalmente.

De las hectáreas de superficie contempladas en el Plan Maestro, 9.9\% se destinó para la zona turística, $3.3 \%$ para zona urbana; $40.6 \%$ para conservación ecológica y $46.1 \%$ para otros usos, por lo que el desarrollo adoptó un carácter turístico-inmobiliario, más que turístico-portuario (FONATUR-BMO, 2006 y FONATUR, 2010). Durante la etapa de planeación el proyecto turístico se encontró circunscrito a las bahías de Santa Cruz, Chahué y Tangolunda; para los trabajos iniciales se construyó el bulevar costero que comunica a las tres bahías y conecta a Santa María Huatulco con el centro turístico, además se reservó una superficie de 1.400 hectáreas, donde se edificó el aeropuerto internacional de Huatulco (De la Madrid 2011 y FONATUR 2010).

Dadas las características de la región se rechazó el modelo de alta densidad hotelera, estableciendo un esquema inmobiliario y hotelero de baja densidad que se desarrolla en mesetas y playas laterales, aprovechando los recursos y características peculiares del lugar. De esta forma, las playas centrales se destinaron a usos recreativos e instalaciones hoteleras y comerciales, mientras que a las zonas planas se les asignó una utilización urbana. Luego entonces, se establecieron usos de tierra para el sistema Santa Cruz-Chahué-Tangolunda, donde la primera bahía, Santa Cruz, dio albergue a un poblado típico (según la perspectiva de los planificadores), en torno a dos plazas públicas y al malecón central, con múltiples opciones recreativas. La segunda bahía, Chahué, fue destinada para alojamientos turísticos de baja densidad (condominios, tiempos compartidos) en su frente de playa, mientras en su valle de acceso se asentara la zona urbana de habitantes permanentes: "La Crucecita". En la tercera bahía, Tangolunda, se contempló la construcción de algunos hoteles, un fraccionamiento residencial y así como un campo de golf (De la Madrid, 2011).

Por estas características puede afirmarse que la construcción del CIP Huatulco modificó de manera radical todo el espacio social de las comunidades involucradas, creando al vapor una nueva espacialidad, en el entendido que hablar del espacio es hablar de hombres y mujeres que construyen diversas formas de vida social en distintos espacios, puesto que "vivir en cualquier espacio del planeta implica una valorización objetiva de la superficie de la Tierra; una agregación del trabajo objetivado que pasa por las representaciones que se establecen sobre el espacio y la producción de espacio" (Talledos Sánchez, 2012; 54).

El espacio como resultado y condición del proceso social, no es inerte, sino un principio activo que recibe cargas sociales de significación y las refleja hacia la sociedad sugiriéndole una multiplicidad de símbolos, discursos y prácticas rituales, y formas diversas de organización social producen y recrean el espacio (Talledos Sánchez, 2012). De esta forma, la transformación espacial de un lugar por la implantación de infraestructura turística no es un proceso pasivo puesto que modifica las relaciones sociales, políticas, económicas y el medio ecológico anterior.

Otra consecuencia de esta nueva espacialidad, fue la migración de personas de estados vecinos como Chiapas y Guerrero y de muchos municipios vecinos de Samahua o Santa María Huatulco. Personas que llegaron atraídas por la demanda de trabajo de la industria de la construcción, primero, y luego por los servicios turísticos, así como empleados y empleadas domésticas de las nuevas residencias, muchas de ellas de turismo alemán y canadiense. Migrantes que arribaron al municipio con su estilo de vida, valores, costumbres y cosmovisiones que contribuyeron a crear un espacio 'alter-ado', en el sentido de entrar en contacto con la alteridad, con el otro y con lo otro, lo nuevo, lo diferente, lo "alter - nativo".

\section{Resultados}

\section{La 'fragilidad natural' de la mujer: contenido hegemónico}

La representación social hegemónica de género basa su fuerza en el hecho de la "sexua- 
ción", la cual propicia que se vean como "naturales" las disposiciones construidas culturalmente. De esta manera, las personas encuentran la "esencia" de cada sexo en las características biológicas que los distinguen, esta atribución transforma la historia en naturaleza y la arbitrariedad cultural en natural (Bourdieu 2000), a partir de ello se distingue lo que es propio de las mujeres (lo femenino) y lo que es propio de los hombres (lo masculino).

Asimismo a las mujeres se atribuye una serie de cualidades "irremediables" o típicamente femeninas: frágiles, hogareñas, poco dotadas para las empresas intelectuales y físicas, dulces, tiernas, emotivas, intuitivas, sensibles, pasivas, frívolas, sumisas, miedosas, dependientes, aptas para las letras y las manualidades, curiosas, indiscretas, parlanchinas y hasta las más negativas: traidoras, envidiosas, incapaces de ser buenas compañeras entre ellas, indisciplinadas, desobedientes, astutas, celosas. Este discurso simbólico remite a una "naturaleza femenina" morfológica, biológica y psicológica, a una "debilidad" natural y congénita en las mujeres (Heritier 1991).

Este contenido hegemónico de la representación social se puso de manifiesto cuando las mujeres asumen como "natural" su fragilidad en oposición a la fuerza física del hombre. Dicho de otra manera, tal fragilidad congénita de las mujeres constituye el themata o hard core, la parte no cognitiva, conocimiento irreflexivo, inconsciente, escasamente cuestionado.

“...no puedes cargar cosas, una mujer es más frágil para cargar bultos, pero el hombre si" (María, ama de casa).

“...mire, si lo vemos por ese lado, pues si porque claro que somos iguales y valemos lo mismo, nada más que, cómo le diré, cambiamos por ser género, pero de que somos iguales yo siento que somos iguales. Que hay trabajos que no podemos hacer, pues hacer algo pesado, no podemos compararnos con hombres y a veces decimos que, tenemos esa palabra de -si yo fuera hombrelevantaría esto, limpiaría esto, no le pidiera ayuda de levantar esto, que yo no puedo, porque es una más frágil, porque eres una mujer no resistes en hacer lo que es pesado; pero de ahí en fuera" (Adalberta, ama de casa).

Tal diferencia de fuerza física entre hombres y mujeres lleva a justificar la asignación de trabajos en el sector turismo, así se legitima la desigualdad.

“(En la cocina de un hotel) Si, ellos tienen más, por decir cuando hay 200 gentes, uno como mujer es más débil y no aguanta, y el hombre es más duro y siempre la mayoría son chef y son muy pocas las mujeres que son chef, porque es muy pesado" (Adalberta ama de casa).

Otras consideran que aunque físicamente son iguales, las mujeres no realizan trabajos pesados porque se cuidan, ya que tienen partes delicadas en su cuerpo y por estética.

“...a veces el hecho de que tú vas a un trabajo, lo primero es: qué sabes hacer y piensan a veces que es un trabajo duro, por decir una mezcla no la puedo hacer como mujer, pero claro que la puedo hacer; lo que cambia aquí es que nosotros como mujeres cuidamos otras cosas; no es que por el hecho de que sean trabajos pesados no los pueda hacer; los puedo hacer, pero cuidamos un poquito más, por decir nuestra estética, nuestras manos, nuestro cuerpo, tenemos partes más delicadas, pero de que podemos hacerlo, podemos hacerlo" (Sory encargada de una casa de huéspedes). 
No obstante, pareciera que el contexto social y geográfico es muy importante en la diferencia física entre géneros percibida por las mujeres, ya que el trabajo turístico estaría implicando una mayor democratización, así como el hecho de haber estudiado.

“....ahora sí, ya entra mucho lo que es el estudio, si tienes estudio pues si somos iguales y puedes tener las mismas oportunidades, pero de ahí en fuera de que tú digas el hombre hace esto y yo no lo puedo hacer, porque es pesado a lo mejor por eso, pero yo lo intento hacer, como yo le digo a mi esposo, yo si me voy a la cocina te puedo ayudar porque todo eso ya lo sé, pero claro si viene acá un campesino, no me puedo comparar porque ya es más pesado, el campesino se va con su machete y a cortar árboles grandes, entonces ahí no me puedo comparar con eso, pero lo que es en casa lo más fácil si lo puedo hacer" (Adalberta, ama de casa).

“Aquí trabajo, yo digo que no hay diferencia, en esos trabajos, porque como hay camaristas pueden haber recepcionistas, como puede haber meseras, guías de turistas, no son trabajos que diga yo que son especialmente para hombres, aquí yo pienso que va a ganar el trabajo, el que tenga la habilidad para poder hacerlo" (Elda, empresaria).

Asimismo, en los testimonios queda plasmada la noción de que una mujer debe cuidarse físicamente: en ese sentido, dos mujeres dejaron ver que la apariencia física es importante.

"(Una mujer debe) cuidarse mucho, la forma de su aspecto de ellas: estar bien arregladas; bien guapas ¿no?” (Ana, ama de casa).

"para verme bonita, para agradarles a los hombres, porque soy vanidosa también” (Elda, empresaria).

Lo anterior tiene que ver con la idea de que las mujeres deben verse bonitas, guapas y casi siempre para gustarle a los hombres, una construcción social ampliamente documentada en los estudios de género que se ha denominado "ser cuerpo para otros". Asimismo, es necesario ser más cuidadosas con las niñas porque son más delicadas que los niños y esta representación social se va constituyendo desde la infancia.

"bueno con mi hija soy mucho más cuidadosa, porque es niña, será porque traemos esa idea en la cabeza, pero son las mismas reglas para hombres y mujeres $(. .$.$) porque siento que las niñas son más delicadas por ser mujeres"$ (Elda, empresaria).

Con respecto a las mujeres que realizan labores que culturalmente no corresponderían a ellas, opinaron:

“- ¿Usted qué piensa de las mujeres policías que hemos visto en Huatulco?

- Pues yo digo que es floja, que nada más le gusta estar sentada y no le gusta trabajar, con esa arma en la mano, porque hay tantas cosas que hacer, ponte un negocio o haz algo.

- ¿Y en el caso de las taxistas?

- Pues también, por estar sentadas en el volante y no hacer un quehacer doméstico, por decir en los hoteles les dan muchas oportunidades a las mujeres" (Rocío, restaurantera). 


\section{De lo privado a lo público: contenido emancipado}

Desde la organización social por género, la cultura le asigna tareas y roles diferente y complementario al hombre y a la mujer. Así en la mayoría de sociedades al hombre le corresponde el trabajo productivo para convertirse en el proveedor, el protector y la autoridad de la familia. Por su parte, a la mujer se le pide que asuma el trabajo reproductivo: el cuidado de los hijos, los enfermos, los ancianos y las labores domésticas. Dicha distribución se basa en la idea de las diferentes capacidades y destrezas entre hombres y mujeres que fundamentan tal atribución diferencial. El hombre es el proveedor y la mujer tiene su lugar en casa cuidando a los hijos.

No obstante, esta asignación de roles sociales se ha modificado por las crisis económicas y ante la incapacidad del esposo por sostener a la familia. Así uno de los efectos económicos reportados en destinos turísticos es el aumento en el costo de la vida. El alquiler de la vivienda, el precio de los alimentos, ropa, transporte, etc. se incrementa como consecuencia de la llegada de turistas. Por otra parte, junto con los turistas llegan al lugar migrantes por las oportunidades de trabajo y de negocios; ambos, turistas y migrantes, traen consigo modelos de vida y aspiraciones que pronto se propagan entre la población nativa: Una y otra circunstancia obliga a las mujeres a buscar un trabajo remunerado en hoteles, restaurantes, agencias de viaje, transporte, es decir, empresas que atienden a los turistas, pero también en comercios, talleres artesanales, escuelas, hospitales que también llegan con y por el turismo. De esta forma, las mujeres 'deben' salir del espacio privado, el doméstico, para incorporarse en el trabajo asalariado, lo público, antes reservado para el hombre.

“...si es difícil para mí, pero si es claro que es muy necesario ayudarle al esposo, por lo mismo que todo está caro, que los hijos piden. [De las mujeres que no trabajan] pienso que es un poco difícil para ellas porque siempre, hay personas que nada más están esperando a su marido, yo me salgo y vendo aunque sea 100 o 200 pesos, a lo mejor no viene a tiempo el marido y si se me antojó comer algo, lo compro o a mis hijos. Por ese lado me gusta tener mi dinero y si no trabajara pues voy a estar esperando que él me traiga dinero, para que pueda comprar o pueda comer, si no lo tienes es muy difícil salir sin dinero y con hijos porque los hijos te va a pedir, el hijo te va a pedir y si no tengo dinero me siento mal, entonces por ese lado yo siento que es muy difícil la situación sin trabajar y estar esperando que el marido venga" (Adalberta, ama de casa).

Este hecho, les lleva a alcanzar una independencia económica que les ayuda a adquirir confianza en sí mismas y a tomar decisiones posteriormente. Es frecuente escuchar entre las mujeres de Huatulco, la afirmación de que nos les gusta depender de alguien para comprarles a sus hijos y a ellas mismas.

"Porque somos en cierta forma independientes de nuestros gustos, no podemos depender de una persona y decir; si me gusta esto ¿me lo compras? Igual si tienes a tu pareja y le dices me gustó este vestido y él te dice en otra ocasión, te quedas tú con eso. A mí me ha pasado, un ejemplo, yo vendo sandalias tejidas y una amiguita que tengo, y ella trabajando, le ofrecí las sandalias, se las mide y le quedan, y agarra y se las enseña a su esposo y él dice nada más que no, a ella le encantaron, se quedó con el gusto y no, entonces yo agarro y le digo, si te gustan cómpratelas, tú trabajas y entonces por ese lado me dice que es importante tener un ingreso" (Sory, encargada de casa de huéspedes). 
"[¿Cómo te sientes de tener tu dinero?] Me siento bien porque es mío y yo lo gané, a estar esperando que me lo den" (María, estudiante).

Salir a trabajar puede constituir un triunfo para algunas mujeres que siguen enfrentando la oposición de sus maridos.

“[¿A usted le gustaría trabajar?] A mí sí, lo que pasa es que mi esposo, después de que nació mi hijo, ya no quiso que yo trabajara, pero de hecho ahorita estamos en que me voy a trabajar, porque apenas tendrá como unos 3 o 4 meses iba a meter papeles en secreto y me rompió los papeles" (Sonia, ama de casa).

"pues la verdad, ya se arrepintió que saliera a trabajar porque gano más que él, ya no quiere que yo trabaje, quiere que me quede en casa, pero después de un año te acostumbras a estar trabajando" (Silvina, inspectora de playa).

En otros casos, tanto padres como maridos no sólo no les impiden, sino las alientan para que salgan a trabajar para llevar dinero a la casa.

“[¿Qué opina su esposo de que usted trabaje? Él realmente dice que como yo me sienta a gusto, a él le da lo mismo si trabajo o no, es lo mismo para él. Los seis meses que yo no tengo trabajo allá, le digo, es que ya quiero trabajar en otra cosa, ya me aburrí, pues busca, por mí no hay problema, me dice. Le dije que quería trabajar porque ya me aburría mucho aquí en la casa y me dijo "pues busca trabajo y si encuentras ve a trabajar" (Rosana, encargada de limpieza).

"Cuando yo trabajaba ahorrábamos para comprar el terreno y cuando salió lo del terreno pues lo compramos y lo pagábamos cada mes ya si lo invertía, pues ya ve que acá el dinero no rinde, lo poquito, todo está caro y pues asî" (Adalberta, ama de casa).

"Te casaste con él, según para que te mantenga, que si lo ayudas, porque desgraciadamente como te lo he dicho, no alcanza el sueldo de un marido y de las que no trabajan pues son conformistas, se conformaron con lo que tienen y por eso hay tanta mujer que se queja de que no tiene dinero, que no tienen para esto, pues si no trabajas, mi’ja no te va a bajar del cielo el dinero" (Barbie, comerciante).

Una característica de la mayoría de las mujeres de la costa oaxaqueña es que siempre han trabajado: vendiendo tortillas, tamales, lavando y planchando ropa, pero el turismo les proporciona mayores oportunidades de empleo como camaristas, cocineras, recepcionistas, meseras, guías, empleadas en tiendas de todo tipo; no obstante, han visto que tales oportunidades se amplían más a partir de estudiar. Muchas de las entrevistadas comentaron que no tuvieron oportunidad de ir a la escuela por la falta de recursos económicos y por la premura de entrar a laborar, pero además porque muchos padres argumentaron que la mujer no debía estudiar porque su destino era el matrimonio, por lo que se consideraba inútil.

" Sí, porque si se casan ya no van a estar esperando a que su marido llegue y él le tenga que dar para la semana lo que sea para mantener los hijos, ya trabajando ella hay mejores ingresos para la familia" (María, estudiante).

“si es niña me gustaría que estudiara más para que no esté atenida a lo que el 
esposo, porque ya ve hay casos de que hay padres de que como es mujer no la apoyan, y es cuando más se debe de apoyar, es un mujer y si algún día el esposo ya la dejó, pero ella va a salir adelante porque está preparada, no va a depender de nadie, del esposo, tenga uno o dos hijos los saca adelante con su profesión, entonces por ese lado es bueno estar preparada, no estar atenida del hombre, ella demostrar que ella puede" (Adalberta, ama de casa).

No obstante, los roles no se han invertido, en ocasiones debido a que el hombre no acepta adoptar el papel de reproductor y otras ocasiones, porque la misma mujer no admite que su marido no abastezca a la familia:

“...a la vez hace daño porque cuando yo trabajé en el hotel y cuando trabajé un tiempo en México, él como que echaba concha, pues ¿ya vas a cobrar, préstame no? o pagas tú ahora, y una dice bueno yo pago o de plano qué vamos hacer (...) yo me hubiera protestado si se hubieran cambiado los papeles como realmente es, yo me voy a trabajar, regreso, la casa está recogida, la comida ya está hecha, mi ropa ya está lavada, nada más para yo levantarme, bañarme, cambiarme pero no, era de también venir y ¿Qué vas hacer de comer? ¿Qué no hay ropa que lavar?, entonces ahí ya no estaba la balanza igual, es por eso que por un lado yo decidí ya no buscar otro trabajo" (Ana, ama de casa).

"Es difícil, porque uno como mujer acostumbra al esposo a que nada más esté y al rato lo hace uno inútil porque ya no hacen nada, nada más andan detrás diciendo qué hago o dime en qué te ayudo, no toman ninguna decisión. Yo lo he dicho y a muchas amigas se los he dicho, no se echen la responsabilidad porque hace uno inútil al marido" (Rocío, dueña de restaurante).

\section{Mujeres empoderadas: contenidos polémicos}

Según Lagarde y de los Ríos (s/f) en la propia subjetividad, empoderarse es desarrollar la conciencia de tener el derecho a tener derechos, reconocer la propia autoridad y confiar en la capacidad de lograr propósitos. Dicha autoridad se produce cuando cada mujer genera autoconfianza, seguridad subjetiva y legitimidad para ser quien es y para existir, es decir, para autoafirmarse y atreverse a tomar decisiones propias y movilizarse para realizarlas en la existencia. Empoderarse de manera personal se concreta en la individuación, es decir, en la transformación personal en un ser individual: único e independiente, con personalidad y concepciones propias, con capacidad de decidir.

Así, el deber ser femenino patriarcal, representación social hegemónica de la mujer, queda trastocado por el empoderamiento. En este sentido, salir de la moral hegemónica y apropiarse de una ética de la mismidad es uno de los grandes trances políticos personales y colectivos para las mujeres.

"Pues fíjese que aquí todo el tiempo que he tenido el negocio lo llevé yo, él casi no se metió, el personal, todos conmigo, yo pago, yo muevo todo, él nada más hacia presencia, él falleció y yo me quedé en el mismo nivel con mi negocio, no se me complicó nada, porque todo el tiempo yo lo llevé, aun si estuviera él, yo tenía las riendas del negocio creo que tenemos la misma capacidad hombres y mujeres para trabajar, y a veces trabajamos y tenemos mejores trabajos las mujeres que los hombres" (Sonia, dueña de restaurante).

"Nosotras como mujeres valemos mucho y siempre tienes que hacer valer tus 
valores, porque si no imagínese y cuanta mujer no hay así que depende mucho del marido, se cierra, yo no, yo administro, yo todo porque el hombre no cuida" (Barbie, comerciante).

"Yo creo que una mujer debe ser con mucha autoestima, muy segura de sí, valiente, a no tener miedo a nada, porque este mundo no va a cambiar si nosotras las mujeres no nos agarramos bien los ovarios y dejar atrás ideas, creencias (...) pues que la mujer es para la casa y él único que tiene derecho a salir es el hombre y que el hombre es quien manda en la casa, que mucho tiempo me marcaron en el matrimonio también, pero le digo ya después rompí con eso y lo mismo le enseño a mi hija, que mujer tiene los mismos derechos que el hombre y la mujer tiene que ser decidida, luchona, por lograr lo que quiera hacer en la vida" (Elda, empresaria).

"Yo he considerado que la mujer es más fuerte, la mujer aguanta más cosas y a veces somos más luchonas, que no nos caemos tan fácilmente y el hombre no, porque el hecho, simplemente de que no hay trabajo, lo ven como que está canijo o está de la fregada, son más negativos y la mujer no, porque pensamos que primeramente Dios, vamos a salir adelante, que van a venir tiempos mejores y no nos caemos tan fácilmente y el concepto para mí de mujer, es decir que es todo, una mujer para mi vale mucho" (Sory, encargada de casa de huéspedes).

\section{Mujeres y Turismo en Huatulco}

Por la perspectiva émic que se buscó incorporar en este estudio, se les interrogó a las mujeres entrevistadas si creían o consideraban que el turismo había provocado cambios en la forma en que ellas se veían a sí mimas, la respuesta fue positiva, pues las informantes adjudican al turismo la forma en que ahora son, estos cambios van desde emular la vestimenta y el comportamiento de los turistas -efecto demostración-, hasta el "abrir los ojos":

"Gracias al turismo que nos visita nacional e internacional, la gente aprende más y se despierta más. Por el trato con el... turismo que llega nos vienen a enseñar, nos vienen a dejar dinero" (Sonia, dueña de restaurante).

“Tú ves y dices: ¡Ah! Mira. Yo en mi negocio, yo no era así como soy ahora. Yo era más... sumisa. Veo, yo trabajo con turismo nacional e internacional, yo aprendí de ellos muchas cosas, me vinieron a enseñar y me vienen a dejar dinero. Estoy trabajando, veo la fila: ¡Ah! Mira cómo se arregla, mira cómo se ve, cómo vienen...yo también quiero, por qué no me voy a arreglar, me voy a comportar. Antes ni me pintaba las uñas, ahora me pongo uñas" (Delia, renta equipo de snorkel y paseos en lancha).

Bahías de Huatulco como destino turístico es lugar propio para el encuentro de culturas, esta situación la tienen clara las mujeres entrevistadas y saben que en todo contacto culturas hay intercambios.

"Yo he visto que si porque viene gente de otros estados con otra cultura y aquí como todavía es un pueblo, venimos con ideas... de la educación que nos dieron, son ideas erróneas, entonces cuando viene gente de otro lado te hacen ver cosas desde otro punto de vista, que no es así, entonces el turismo nos ha abierto mucho los ojos" (Elda, empresaria). 
El turismo es percibido como un factor que les permite superarse y vivir mejor, esto debido a los ingresos que les proporciona y por las oportunidades de trabajar o estudiar, situación que no tuvieron sus padres.

"El turismo nos ha cambiado la vida porque por el trabajo que tengo, el turismo nos ayuda a la economía sobre todo, nos ha ayudado a seguir adelante, a estudiar por ejemplo. De ahí sale para los zapatos y verme bonita" (Elda, empresaria).

Sin embargo, no es común escuchar que los turistas también aprenden de los habitantes de Bahías de Huatulco, por ello es de destacar el testimonio de una mujer que lo ha logrado concebir.

"El turismo viene a dejarnos una derrama económica, pero nosotros les enseñamos a valorar la naturaleza y les enseñamos a ellos a que tenemos que cuidar las cosas que ellos vienen a disfrutar y un ejemplo son muestras playas que a ellos les enseñamos a mantenerlas limpias porque ellos son los que vienen también a disfrutar de este lugar maravilloso que tenemos. En cuestión de aspectos personales, admiramos a una persona que viene de la ciudad porque es diferente la ciudad a un lugar pequeño. Huatulco es un lugar pequeño que no tenemos tanto negocios, vestimenta, tiendas" (Sory, encargada de casa de huéspedes).

"Si eres tantito lista, pues aprovechas y absorbes lo bueno y lo positivo, y lo que te puede ayudar a mejorar" (Sonia, dueña de restaurante).

\section{Comentarios Finales}

Para el caso que nos ocupa, la representación social de género, el núcleo central es un núcleo hegemónico: aún se escucha decir que los hombres son así y las mujeres asado, que tal cosa es cosa de hombres y eso es cosa de mujeres. En palabras llanas se mantiene en muchos casos la idea de que hombres y mujeres están biológicamente determinados para ciertas funciones.

De esta forma, las resignificaciones de la identidad de género estarían a nivel de los elementos periféricos, como representaciones emancipadas debido a que existen diversidad de hombres y mujeres en los que tal componente periférico se encuentra en conflicto o en proceso de transición.

Vale la pena aclarar que dicha resignificación de la representación social de la identidad de género no implica incertidumbre o hablar de identidades light o líquidas (Lipovetsky, 2000 [1986]) sino, desde la filosofía, estamos presenciando el proceso por el cual las mujeres buscan dejar de ser cosas o seres-en-sí, para caminar hacia la posibilidad de ser sujetos, de tener capacidad de nombrar y significar en el mundo a partir de iniciar un proceso de deconstrucción de su representación.

De lo anterior entendemos que la estructura de una representación no se modifica en automático a partir de la modificación del contexto, sino que el contexto modificado se convierte en un detonante para tal reestructuración.

Así como las representaciones sociales hegemónicas de género han persistido a lo largo del tiempo, también es cierto que en todas las épocas ha habido mujeres disidentes, excéntricas o extrañas que se ha negado a seguir el modelo establecido por el sujeto masculino. Mayorbre Rodríguez, por ejemplo, manifiesta que en los últimos tiempos tales posturas discrepantes se han incrementado a partir del cuestionamiento al sistema patriarcal llevado a cabo por el feminismo o los feminismos. No obstante, este proceso de subjetivación que va 
aparejado con una modificación en las representaciones sociales debe surgir de un conflicto cognitivo o de crisis, o de ambos, que no se quede sólo a nivel crítico, reactivo sino que exige haya un cambio de orden simbólico que permita reconceptualizar al sujeto femenino, teniendo en cuenta que no existe "la mujer" sino múltiples mujeres.

Así una representación social es altamente dinámica, sobre todo en la actualidad cuando los cambios son vertiginosos, al tiempo que tiene un núcleo central encarnado en la tradición difícilmente modificable. Este núcleo central ha sido denominado hard core. En el caso de las representaciones sociales de género, este hard, según Banchs Rodríguez (2000) es particularmente resistente al cambio. La polifacia cognitiva le da a la vez un carácter dinámico y estable, dos caras de una misma moneda: recuerdo/olvido, reviviscencia/fosilización, éste es el meollo medular de este trabajo.

En este sentido, pudo constatarse que la representación social de la mujer en el contexto turístico de Bahías de Huatulco incluye contenidos hegemónico: la mujer es frágil; contenidos emancipados: la necesidad y el placer de trabajar y contar con su propio dinero; y contenidos polémicos: la mujer es tan o más capaz que el hombre. Por ello, se observó que la representación social de la mujer no es una estructura monolítica porque se está modificando por el contexto turístico.

Entonces ¿cuál es la importancia del turismo en este proceso de cambio en las mujeres? Apuntamos que un destino turístico como Huatulco pensado para el turismo extranjero favorece que dichos cambios se produzcan de forma más rápida de lo que sucede en otros espacios -ecoturismo, por ejemplo (ver Díaz Carrión 2010 y 2012)-, de esta forma dicho encuentro de culturas favorece que los cambios socioculturales tanto en hombres como mujeres por su rapidez sean más notorios y más variados. Este hecho es percibido por las mujeres cuando ellas que viven en Bahías de Huatulco se comparan con las que viven en las pequeñas comunidades no turísticas que les rodean.

\section{Bibliografía}

ABRIC, Jean Claude

1993 "Central system, peripheral system: Their functions and roles in the dynamics of social representations". Electronic Version, Papers on Social Representations. Vol. 2 (2), pp. 7578.

2001 Prácticas sociales y representaciones. Ediciones Coyoacán, S. A. de C. V. México

BANCHS RODRÍGUEZ, María Auxiliadora

2000 "Representaciones sociales, memoria social e identidad de género" Akademos. Vol. II, no. 1, pp. 59-76.

2001 "Identidades de género en la encrucijada. De la sociedad matrilineal al umbral de la posmodernidad." En QUINTERO, M.P. (coord.). Identidad y Alteridades. Mérida: Fascículo de AVESPO 10.

BRENNER, Ludger.

2005 "State-Planned Tourism Destinations: The Case of Huatulco, México". Tourism Geographies. Centro de Estudios de Geografía Humana, El Colegio de Michoacán, México. Vol. 7, No. 2, pp. 138-164.

BOURDIEU, Pierre.

2003 La dominación masculina. Barcelona, Anagrama.

CONES. Cynthia

1995 "Crafting selves. The lives of two mayan women". Annals of Tourism Research 22(2): 314-327

DE LA MADRID, Miguel

2011 “Bahías de Huatulco". Crónica del sexenio 1982-1988, Agosto 1987. Disponible en http:// www.mmh.org.mx/nav/node/190 
DIAZ CARRIÓN, Isis Arlene.

2010 "Ecoturismo comunitario y género en la Reserva de la Biósfera de Los Tuxtlas (México)". Pasos. Revista de Turismo y Patrimonio Cultural. Vol. 8, No. 1: 151-165

2012 "Turismo de aventura y participación de las mujeres en Jalcomulco (México)" en Pasos. Revista de Turismo y Patrimonio Cultural. Vol. 10, No. 5: 531-542

GARCÍA RAMÓN, María Dolors CANOVES, Gemma y VALDOVINOS, Nuria

1995 "Farm tourism, gender and the enviroment in Spain" Annals of Tourism Reseach. 22(2): 267282

GIDDENS, Anthony

1995 La constitución de la sociedad: bases para la teoría de la estructuración. Amorrortu, Madrid.

HÉRITIER, Francoise.

1991 "La sangre de los guerreros. La sangre de las mujeres". Alteridades, 1 (2): 92-102

IBAÑEZ, Tomás

1988 Ideologías de la vida cotidiana. Barcelona: Sendai.

JODELET. Denise

1984 "La representación social: fenómenos, conceptos y teoría". En MOSCOVICI, Serge. Psicología social II. Pensamiento y vida social. Psicología social y problemas sociales. Barcelona-Buenos Aires-México: Paidós

LAGARDE Y DE LOS RÍOS, Marcela

(s/f). $\quad$ Vías para el empoderamiento de las mujeres. Agrupación para la Igualdad en el Metal. Disponible en http:// http://www.femeval.es/proyectos/ProyectosAnteriores/Sinnovaciontecnologia/Documents/ACCION3_cuaderno1.pdf

LAKOVIDOU, Olga.

2002 "Women's agrotourist cooperatives in Greece: key elements for their successful operation". Journal of Rural Cooperation. 30(1): 13-24

LAMAS, Marta.

2007 "Complejidad y claridad en torno al concepto género." En GIGLIA, Angela., GARMA, Carlos. y DE TERESA, Ana. Paula. (comp.). ¿A dónde va la antropología? División de Ciencias Sociales y Humanidades de la UAM- Iztapalapa, México.

LIPOVETSKY, Gilles

2000 La era del vacío. Ensayos sobre el individualismo contemporáneo. Barcelona, Anagrama.

LÓPEZ GUEVARA, Víctor Manuel

2000 "La reorientación del ciclo de vida del área turística: El caso de Bahías de Huatulco, Oaxaca (México)". Investigaciones Turísticas. N 1, pp. 107-121

MALLEMACI, Fortunato y GIMENEZ BÉLIVEAU, Verónica.

2006 "Historia de vida y métodos biográficos" en VASILACHIS Irene. (coord.) Estrategias de investigación cualitativa. Argentina, Gedisa

MENDIZABAL, Nora

2006 "Los componentes del diseño flexible en la investigación cualitativa". en VASILACHIS, Irene (coord.). Estrategias de investigación cualitativa. Argentina, Gedisa

MCKENZIE GENTRY, Kristine.

2007 "Belizean women and tourism work. Opportunity or impediment". Annals of Tourism Reseach. 34(2):477-496

MORALES GÓMEZ, Mario

2009 Turismo y tenencia de la tierra en la costa de Oaxaca: Los casos de Mazunte y San Agustinillo. Tesis de licenciatura en antropología social. UIA, Puebla, México

MOSCOVICI, Serge

1961 El psicoanálisis, su imagen y su público. Buenos Aires, Argentina: Huemul S.A

1989 "Des représentations collectives aux representations sociales: elements pour une histoire." En JODELET, Denise (ed). Les Répresentations Sociales. París. Francia: PUF

NOGUÉS, Antonio Miguel (coord.)

$2003 \quad$ Cultura y turismo. Signatura Ediciones de Andalucía, Sevilla.

OROZCO, Patricia.

1992 “Bahías de Huatulco: reseña de la reubicación”. Alteridades. Vol. No. 4, pp. 95-99. 


\section{PETRACCI, Mónica}

2004 "La agenda de la opinión pública a través de la discusión grupal. Una técnica de investigación cualitativa: el grupo focal." en KORNBLIT, Ana Lía. (coord.). Metodologías cualitativas en las Ciencias Sociales. Modelos y procedimientos de análisis. Buenos Aires. Biblos.

RAMÍREZ PLASCENCIA, Jorge

2007 "Durkheim y las representaciones colectivas.” En RODRÍGUEZ SALAZAR, Tania. y GARCÍA CURIEL, María de Lourdes (coord.). Representaciones sociales. Teoría e investigación. Universidad de Guadalajara, México.

RENZI, María Rosa (coord.)

2009 Explorando la ruta de la igualdad: trabajo, género y turismo en Centroamérica. Fondo de Desarrollo de las Naciones Unidad para la Mujer (UNIFEM), México.

RODRÍGUEZ SALAZAR, Tania

2001 Las razones del matrimonio. Representaciones, relatos de vida y sociedad. Guadalajara: Editorial CUCSH-UdeG

2003 "El debate de las representaciones sociales en la psicología social." Relaciones 93, Vol. XXIV, pp. 52-80.

2005 "Los valores de jóvenes mexicanos y españoles: un análisis comparativo", en: Jóvenes en la mira. Revista de estudios sobre juventudes. Guadalajara: Instituto Jalisciense de la Juventud, vol.1, núm. 2, pp. 51-72

2007 "Sobre el estudio cualitativo de la estructura de las representaciones sociales." En RODRÍGUEZ SALAZAR, Tania. y GARCÍA CURIEL, María de Lourdes. (coord.). Representaciones sociales. Teoría e investigación. Universidad de Guadalajara, México.

2011 "Discusiones teórico metodológicas sobre el character contextual de las representaciones sociales." Sinéctica. Revista electrónica de educación. 36. Universidad Jesuita de Guadalajara. Disponible en http://www.sinectica.iteso.mx.

SIGÜENZA, María Carmen

2011 "La mujer en el subsector del alojamiento. El caso de la Costa Blanca (Alicante, España)" Investigaciones Turísticas. No. 2, julio-diciembre, 102-119

SPARRER, Marion

2003 "Género y Turismo Rural. Ejemplo de la Costa Coruñesa". Cuadernos de Turismo, 13: 181-197

SWAIN, Margaret

1989 "Roles de género en el turismo indigenista: las molas de los kuna, Kuna Yala y la supervivencia cultural" en Valene Smith (comp.) Anfitriones e invitados. Antropología del

SWAIN, Margaret Turismo. Endymion, Madrid. 139-170

1993 "Women producers of ethnic crafts." Annals of Tourism Research 20(1): 32-51

1995 "Gender in Tourism". Annals of Tourism Research. 22(2): 247-266

2005 "Las dimensiones de género en la investigación sobre turismo": Temas globales, perspectivas locales. Política y Sociedad. Vol. 42, Núm. 1: 25-37

TALLEDOS SÁNCHEZ, Edgar.

2012 "La imposición de un espacio: de La Crucecita a Bahías de Huatulco". Revista Mexicana de Ciencias Políticas y Sociales. UNAM, Año LVII, núm. 216, pp. 119-.142.

TOURAINE, Alain.

1997 ¿Podremos vivir juntos? FCE, México.

TRANAKJIT Yutyunyong. y SCOTT, Noel.

2009) "The integration of social exchange theory and social representations theory: A new perspective on residents' perception research". Paper at 18th Tourism and Hospitality Education And Research Conference See CHANGE: tourism and hospitality in dynamic world' Hosted by Curtin University of Technology Fremantle Western Australia

TREMINIO SÁNCHEZ, Ilka

2005 "La influencia del turismo en la democratización familiar: una mirada a partir de la socioterritorialidad. El caso de Quepos/Manuel Antonio, Costa Rica”. Revista Centroamericana de Ciencias Sociales. No. 3, Vol. II 
TUCKER, Hazel

2007 "Undoing shame: tourism and women's work in Turkey". Journal of Tourism and Cultural Chang. 5(2): 87-105

VALENCIA ABUNDIZ, Silvia

2007 "Elementos en la construcción, circulación y aplicación de las representaciones sociales" en RODRÍGUEZ, Tania y GARCÍA CURIEL, María de Lourdes (coord.). Representaciones sociales. Teoría e investigación. Universidad de Guadalajara, México.

VANDEGRIFT, Darcie

2008 "This isn't paradise- I'work here". Global restructuring. The tourism industry, and women workers in Caribbean Costa Rica". Gender \& Society. 22(6): 778-798

WILKINSON, Paul F. y PRATIWI, Wiwik.

1995 "Gender and tourism in a Indonesian village" Annals of Tourism Research. 22(1): 283-299 WILSON, D.

1979 "Los primeros efectos del turismo en Seychelles" en Emanuel de Kadt. Turismo ¿Pasaporte al desarrollo? Perspectivas sobre los efectos sociales y culturales del turismoEndymion, España. 